\title{
Humidification in Very-High-Flow Nasal-Cannula Therapy in an Adult Lung Model
}

\author{
Yusuke Chikata, Keisuke Morinishi, and Masaji Nishimura
}

\begin{abstract}
BACKGROUND: High-flow nasal cannula (HFNC) therapy is used for patients with respiratory failure. Recently, HFNC therapy with very high gas flows (ie, gas flows of 60-100 L/min) was reported to generate higher positive airway pressure and an associated decrease in breathing frequency. However, the humidification of HFNC therapy with very high gas flow remains to be clarified. METHODS: We evaluated 3 heated humidifier systems: a single MR850, the Hummax2, and parallel MR850s. The MR850 is a pass-over humidifier system, and the Hummax2 works with a porous hollow polyethylene fiber membrane. The parallel MR850 system included 2 MR850s connected in parallel to the lung with a $22 \mathrm{~mm}$ Y-piece. Gas flow was set at $40-90 \mathrm{~L} / \mathrm{min}$ in increments of $10 \mathrm{~L} / \mathrm{min}$, and $\mathrm{F}_{\mathrm{IO}_{2}}$ was set at 0.21 . Heated humidifiers in the MR850 systems were set in invasive mode $\left(40^{\circ} \mathrm{C} /-3\right)$, and with the Hummax 2 the vapor temperature was set at $39^{\circ} \mathrm{C}$. The simulated external nares were connected to a test lung via a standard ventilator circuit. One-way valves prevented mixing of inspired and expired gases. Compliance of the test lung was $0.05 \mathrm{~L} / \mathrm{cm} \mathrm{H}_{2} \mathrm{O}$ and resistance $5 \mathrm{~cm} \mathrm{H}_{2} \mathrm{O} / \mathrm{L} / \mathrm{s}$. Simulated tidal volumes $\left(V_{T}\right)$ were 300,500 , and $700 \mathrm{~mL}$, with a breathing frequency of 10 or 20 breaths/min and an inspiratory time of $1.0 \mathrm{~s}$. Temperature, relative humidity, and absolute humidity (AH) of inspired gas downstream of the external nares were measured using a hygrometer for $1 \mathrm{~min}$, and results for the last 3 breaths were extracted. RESULTS: With the single MR850, when gas flow was $>80 \mathrm{~L} / \mathrm{min}$, AH decreased as gas flow increased $(P<.001)$. With the Hummax 2 , as gas flow increased, AH decreased $(P<.001)$. With the parallel MR850s, regardless of gas flow, AH was constant. As breathing frequency increased, AH increased in all systems. CONCLUSIONS: During HFNC therapy with very high gas flows in this bench study, conventional heated humidifiers did not provide adequate humidification. Caution is advised when using HFNC therapy with very high gas flows with conventional heated humidifiers. Key words: humidification; heated humidifier; very high flow gas. [Respir Care 2019;64(7):809-817. ㅇ 2019 Daedalus Enterprises]
\end{abstract}

\section{Introduction}

When acute hypoxemic respiratory failure occurs, oxygen therapy is the first line of intervention, and high-flow nasal cannula (HFNC) therapy is now commonly administered to patients with acute respiratory failure. ${ }^{1}$ Delivering up to $60 \mathrm{~L} / \mathrm{min}$ of heated and humidified medical gas via a wide-bore nasal cannula, HFNC therapy has a num-

\footnotetext{
Dr Chikata and Mr Morinishi are affiliated with the Medical Equipment Center, Tokushima University Hospital, Tokushima, Japan. Dr Nishimura is affiliated with Emergency and Critical Care Medicine, Tokushima University Graduate School, Tokushima, Japan.
}

The authors have disclosed no conflicts of interest. ber of physiological benefits, including washout of carbon dioxide in nasopharyngeal dead space, ${ }^{2}$ adequate humidification ${ }^{3}$, accurate maintenance of $\mathrm{F}_{\mathrm{IO}_{2},}{ }^{4}$ low PEEP level, ${ }^{5,6}$ and reduced respiratory effort. ${ }^{7}$

Recently, with a report showing that flows of up to $100 \mathrm{~L} / \mathrm{min}$ result in increased pharyngeal airway pressure of $1 \mathrm{~cm} \mathrm{H}_{2} \mathrm{O}$ per $10 \mathrm{~L} / \mathrm{min}$ of flow, HFNC therapy with very high gas flows (ie, gas flow of $60-100 \mathrm{~L} / \mathrm{min}$ ) has

\footnotetext{
Correspondence: Masaji Nishimura, Critical Care and Emergency Medicine, Tokushima University Graduate School, 3-18-15 Kuramoto, Tokushima, Japan 770-8503. E-mail: nmasaji@ tokushima-u.ac.jp.
}

DOI: $10.4187 /$ respcare. 06417 
been shown to have a greater beneficial effect: as gas flow increases, breathing frequency decreases. ${ }^{8}$ There are few reports of the impact of HFNC therapy with very high gas flows. To deliver constant flow by using wall pressure supply, $60-70 \mathrm{~L} / \mathrm{min}$ is maximal; however, there are no adequate flow meters for flows $>60 \mathrm{~L} / \mathrm{min}$.

The performance of a heated humidifier is affected by gas flow and environmental conditions. . $^{3,9,10}$ In a previous bench study using an adult lung model, under various respiratory parameters and different gas flows, we evaluated the humidification performance of a heated humidifier with HFNC therapy. ${ }^{3,10}$ In this study, we evaluated the adequacy of humidification during conventional HFNC therapy (ie, gas flow of $40-50 \mathrm{~L} / \mathrm{min}$ ) and HFNC therapy with very high gas flows (ie, gas flow of 60-90 L/ $\min )$.

\section{Methods}

\section{Tested HFNC Systems}

We evaluated 3 heated humidifier systems, the MR850 (Fisher \& Paykel, Auckland, New Zealand), the Hummax 2 (Metran, Saitama, Japan), and 2 MR850 systems set up in parallel. The MR850 passes gas directly over exposed heating wires; in the Hummax2, gas flows through a hollow porous polyethylene fiber membrane inside the respiratory circuit. The MR850 has an auto-active compensatory algorithm that continuously monitors gas flow and the temperature of the chamber outlet and the distal temperature probe, adjusting the temperature to prevent excessive condensation. The Hummax 2 is only able to set the vapor temperature between $32^{\circ} \mathrm{C}$ and $39^{\circ} \mathrm{C}$. The parallel MR850 systems included a 22-mm Y-piece that joined flow delivery (see Fig. 1, Fig. 2).

Each humidifier system was set up between the wall gas supply with gas flow through an air/oxygen blender with a very-high-flow regulator (10-90 L/min, OA2080, San-You Technology, Saitama, Japan) and the cannula interface with the model lung. Manufacturer standard respiratory circuits led from the heated humidifiers (MR850 via RT202, Fisher \& Paykel; Hummax2 via R100-H, Metran) to nasal prongs (OPT544, Fisher \& Paykel).

\section{Simulated Spontaneous Breathing}

Spontaneous breathing was simulated using a training test lung (TTL model 1601, Michigan Instruments, Grand Rapids, Michigan). After the muscle and lung compartments of the test lung were connected, the Puritan-Bennett 840 (Medtronic, Minneapolis, Minnesota) inflated the muscle compartment, whereupon the lung compartment inspired medical gas and some ambient via the HFNC. To simulate external nares, we made 2 holes in a polyvinyl

\section{QUICK LOOK}

\section{Current knowledge}

High-flow nasal cannula (HFNC) therapy is widely used for patients with respiratory failure. Normally, during HFNC therapy, gas flow is set to $30-60 \mathrm{~L} / \mathrm{min}$. One advantage of HFNC therapy over other therapies is superior humidification. Recently, HFNC therapy with very high gas flow (ie, with gas flows of 60-100 L/min) was reported to generate higher positive airway pressure and an associated decrease in breathing frequency.

\section{What this paper contributes to our knowledge}

At HFNC flows $>60 \mathrm{~L} / \mathrm{min}$, the 2 tested heated humidifier systems did not maintain the set temperature when used individually. At flows $>90 \mathrm{~L} / \mathrm{min}$, the absolute humidity delivered by the individual heated humidifiers (ie, $<30 \mathrm{mg} / \mathrm{L}$ ) was inadequate. When applying HFNC with very high gas flows, it is expedient to use 2 MR850 devices connected in parallel with a Y-piece.

chloride cylinder closed at one end and connected to the lung compartment of the TTL test lung at the other end via a standard ventilator circuit (Smoothbore tube 5000000, Intersurgical, Berkshire, United Kingdom). One-way valves prevented the mixing of inspired and expired gases (Fig. 3). TTL test lung compliance was $0.05 \mathrm{~L} / \mathrm{cm} \mathrm{H}_{2} \mathrm{O}$, and resistance was $5 \mathrm{~cm} \mathrm{H}_{2} \mathrm{O} / \mathrm{L} / \mathrm{s}$. Simulated tidal volume $\left(\mathrm{V}_{\mathrm{T}}\right)$ was set, with decelerating flow waveform, at 300, 500 , and $700 \mathrm{~mL}$, with a breathing frequency of 10 or 20 breaths/min and an inspiratory time of $1.0 \mathrm{~s}$. These settings resulted in 33,55 , and $77 \mathrm{~L} / \mathrm{min}$ of spontaneous breathing at peak inspiratory flow. To monitor $\mathrm{V}_{\mathrm{T}}$ delivery, gas flow to the lung compartment was measured using a pneumotachometer (4700 series, 0-160 L/min, Hans Rudolph, Shawnee, Kansas) with a differential pressure transducer (TP-602T, $\pm 5 \mathrm{~cm} \mathrm{H}_{2} \mathrm{O}$, Nihon Kohden, Tokyo, Japan). The pneumotachometer was calibrated using a super syringe.

\section{Experimental Procedures}

Both the single MR850 system and the parallel MR850 system were set in the "invasive with auto-active compensatory mode" $\left(40^{\circ} \mathrm{C} /-3\right)$; in the Hummax 2 system, vapor temperature was set at $39^{\circ} \mathrm{C}$. With the single MR850 and the Hummax2, gas flow was set at $40-90 \mathrm{~L} / \mathrm{min}$ in increments of $10 \mathrm{~L} / \mathrm{min}$, and $\mathrm{F}_{\mathrm{IO}_{2}}$ was set at 0.21 . With the parallel MR850 system, the gas flow was divided equally between both devices. 


\section{Simulated Humidification in Very-High-Flow Nasal Cannula}

Single MR850

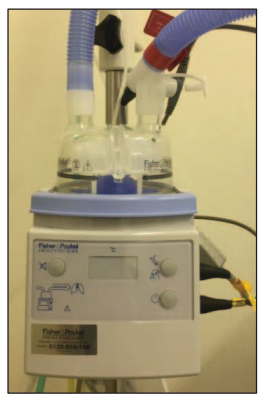

Pass-over type

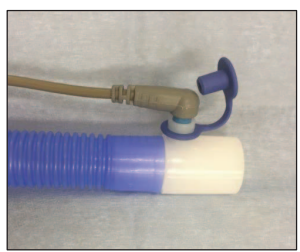

Hummax2

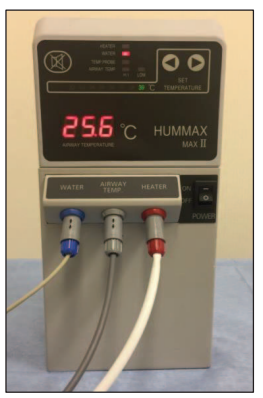

Porous hollow fiber type

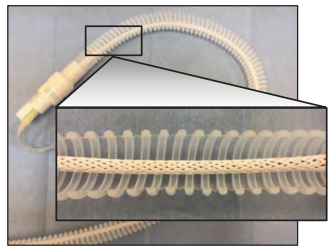

Parallel MR850s

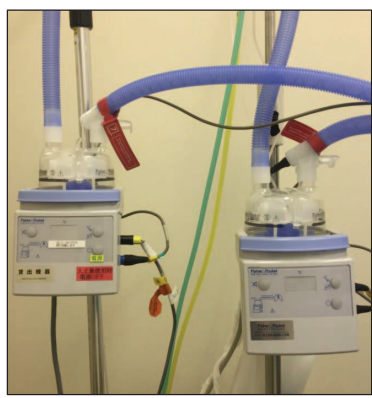

Pass-over type

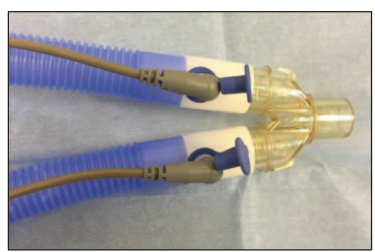

Fig. 1. Tested heated humidifiers. The single MR850 was evaluated as conventional HFNC system, The Hummax2 is a type of porous hollow fiber membrane, it generates vapor in set temperature. The parallel MR850s were used as two gas blenders and heated humidifiers and both tubes were connected in parallel with a $22 \mathrm{~mm}$ Y-piece.

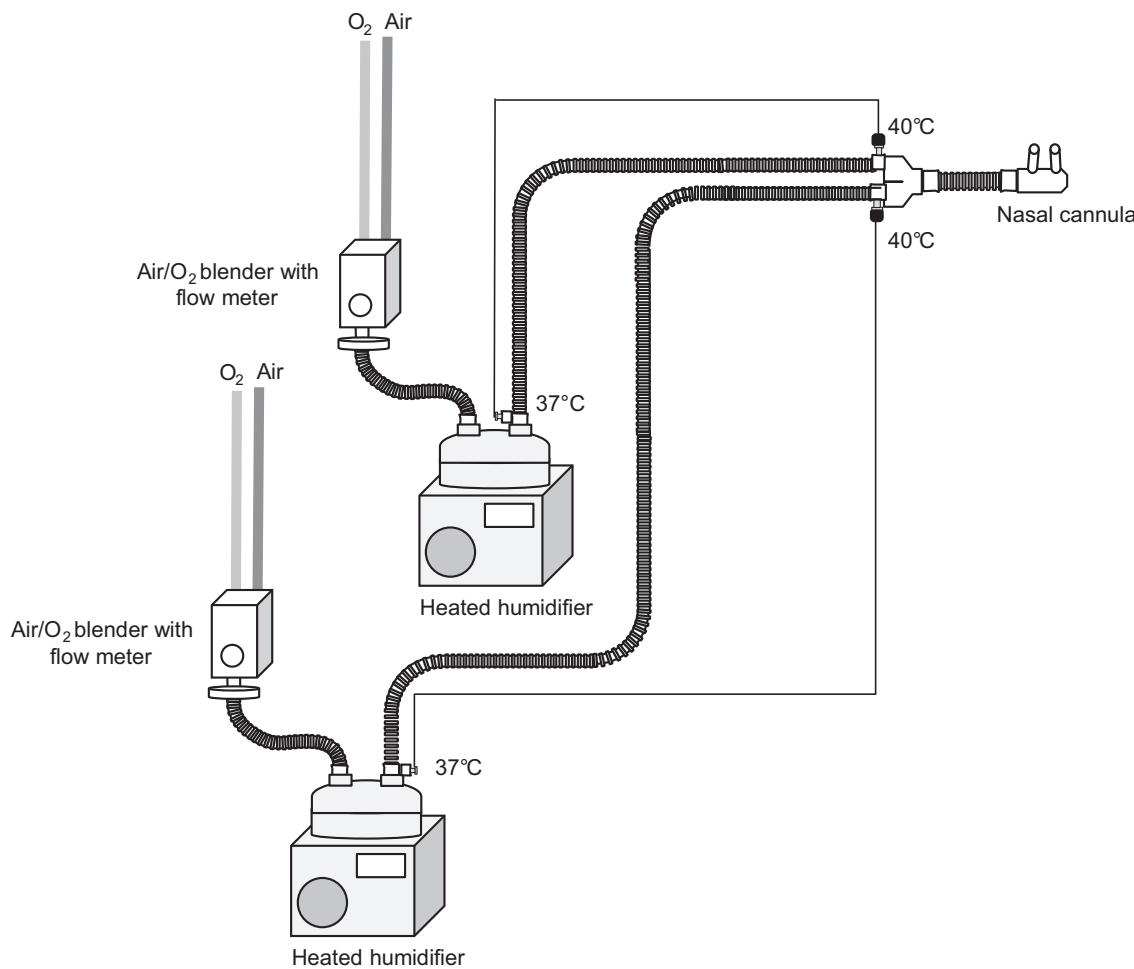

Fig. 2. The parallel MR850 system incorporated two $\mathrm{O}_{2}$ /air blenders with high-flow meter (0-60 L/min), two heated humidifiers, two manufacturer standard circuits and a nasal prong. Outlets of each circuit were connected with a 22 mm Y-piece for joint delivery of the HFNC. The set up of the other two systems was similar, but without the inclusion of a second humidifier and circuit or Y-piece. The temperatures are as set for each MR850.

Before experimental testing, a ventilator self-test was performed. After each experimental setting was changed, we allowed at least 15 min for stabilization. Temperature, relative humidity, and absolute humidity $(\mathrm{AH})$ of inspired gas immediately downstream from the external nares were measured using a hygrometer (Moiscope, Senko Medical, 


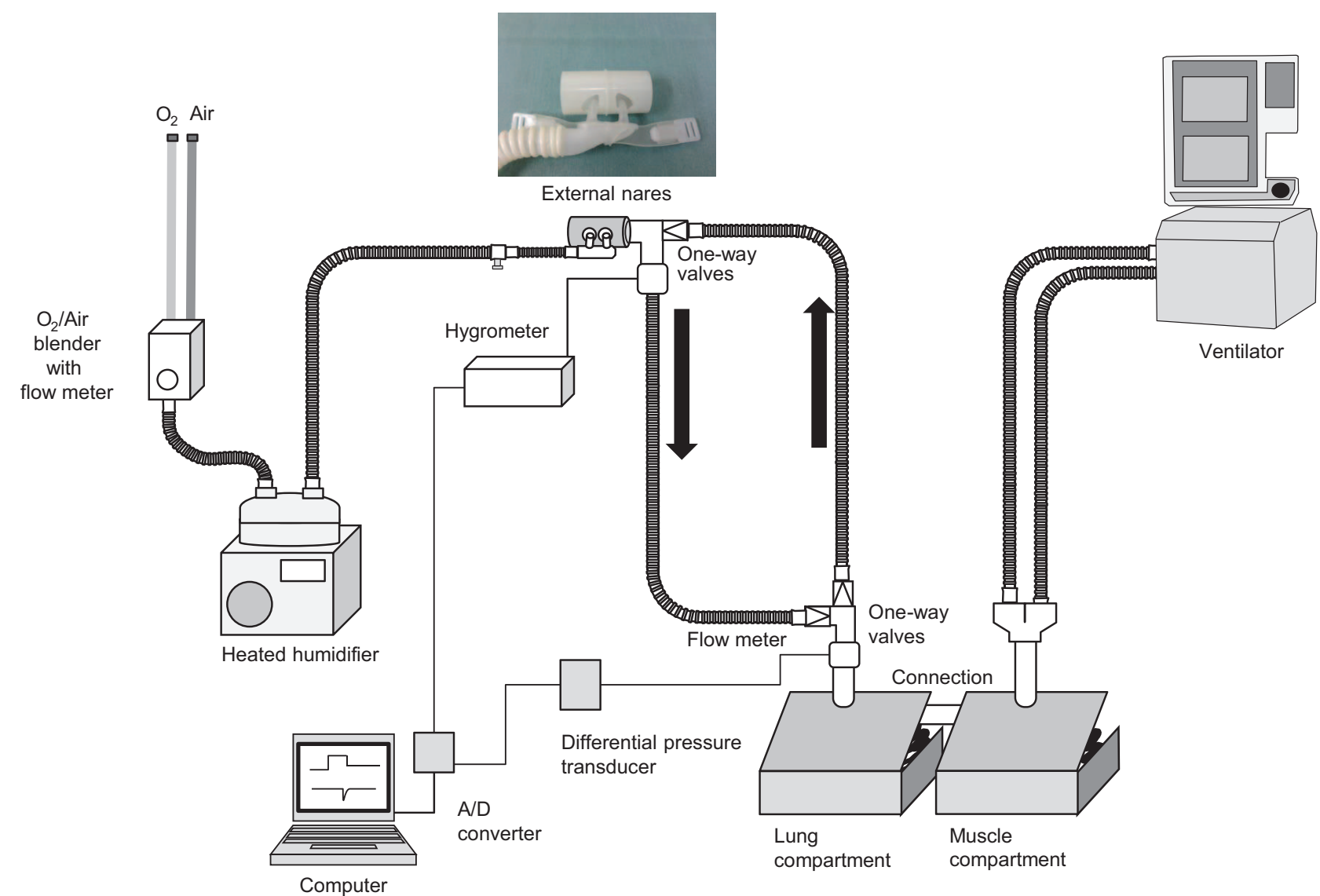

Fig. 3. Spontaneous breathing was simulated using a mechanical ventilator and TTL test lung. To simulate spontaneous breathing, the muscle and lung compartment of the test lung were connected so that the ventilator inflated the muscle compartment, causing the lung compartment to inspire HFNC medical gas and ambient air. One-way valves prevented mixing of inspired and expired gases. During simulated inspiration, medical gas and ambient air are drawn into the lung compartment past the hygrometer. We made two holes in polyvinyl chloride cylinder to simulate external nares. The external nares were connected to the lung compartment of TTL test lung via a standard ventilator circuit. To confirm tidal volume delivered to the lung compartment, flow to the lung compartment was measured using a pneumotachometer with a differential pressure transducer.

Tokyo, Japan) for $1 \mathrm{~min}$, and the results for the last 3 breaths were extracted. The thermometer was calibrated using a cooler/heater water source (HHC-51, Senko Medical). All signals were processed through an analog/digital converter and saved on a computer at $50 \mathrm{~Hz} /$ channel using data acquisition software (WinDaq, Dataq Instruments, Akron, Ohio). The results were expressed as median and IQRs. All experiments were performed in an air-conditioned room where temperature was maintained at $24^{\circ} \mathrm{C}$, and ambient temperature and $\mathrm{AH}$ were monitored.

\section{Statistics}

Repeated measures of analysis of variance were performed. All statistical tests were 2 -sided, and $P$ values $<.05$ were considered statistically significant. All statistical analysis was performed using commercial software (SPSS 11.01, SPSS, Chicago, Illinois).

\section{Results}

Throughout the protocols, ambient AH was $4.6 \pm 2.0 \mathrm{mg} / \mathrm{L}$, and temperature was $24.1 \pm 0.2^{\circ} \mathrm{C}$. During simulated spontaneous breathing, $\mathrm{V}_{\mathrm{T}}$ was measured as $278 \pm 9.5,488 \pm 7.5$, and $682 \pm 9.2 \mathrm{~mL}$ when set $\mathrm{V}_{\mathrm{T}}$ was 300,500 , and $700 \mathrm{~mL}$, respectively.

\section{Effect of Very-High Gas Flow on AH}

At very-high gas flow of $40-90 \mathrm{~L} / \mathrm{min}$, increasing in increments of $10 \mathrm{~L} / \mathrm{min}$, respective $\mathrm{AH}$ readings with the single MR850 system were $33.4 \mathrm{mg} / \mathrm{mL}$ (32.6-34.7), $34.0 \mathrm{mg} / \mathrm{mL}(32.7-36.0), 35.7 \mathrm{mg} / \mathrm{mL}(34.1-36.7)$, $35.4 \mathrm{mg} / \mathrm{mL}$ (34.3-36.5), $31.5 \mathrm{mg} / \mathrm{mL}$ (30.1-33.5), and $29.6 \mathrm{mg} / \mathrm{mL}$ (28.8-31.1); with the Hummax2 system, the respective $\mathrm{AH}$ readings were $34.3 \mathrm{mg} / \mathrm{mL}$ (33.1-35.9), $33.6 \mathrm{mg} / \mathrm{mL}(32.5-35.6), 32.1 \mathrm{mg} / \mathrm{mL}(31.3-33.5)$, $29.5 \mathrm{mg} / \mathrm{mL}(28.0-30.5), 27.8 \mathrm{mg} / \mathrm{mL}(27.0-28.5)$, and 

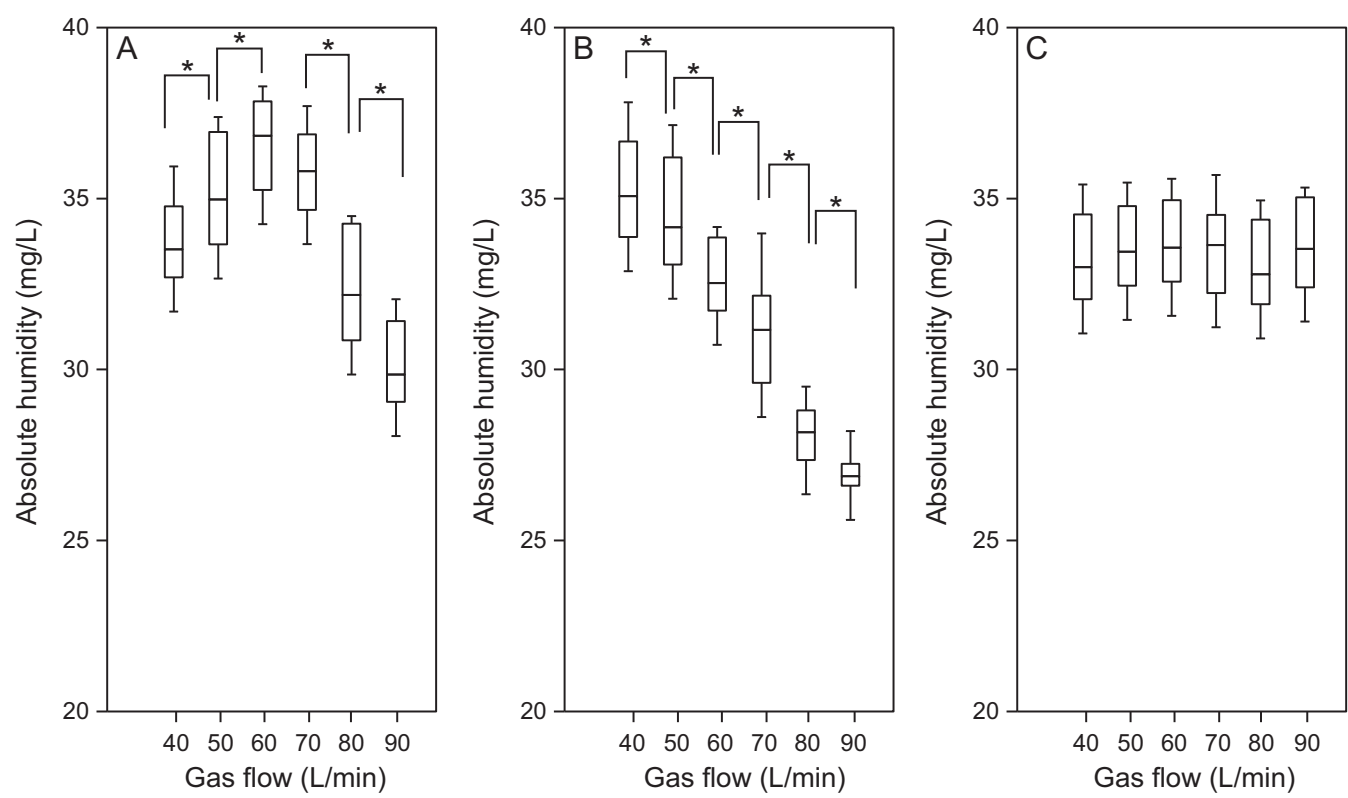

Fig. 4. With the single MR850 (A), at HFNC gas flow 40-60 L/min at each $10 \mathrm{~L} /$ min increment, absolute humidity increased. At HFNC gas flow increments above $80 \mathrm{~L} / \mathrm{min}$, however, absolute humidity decreased. With the Hummax2 (B), as HFNC gas flow increased, absolute humidity decreased. With the parallel MR850s (C), absolute humidity was constant regardless of HFNC gas flow. * $P<.05$.

$26.9 \mathrm{mg} / \mathrm{mL}(26.6-27.2)$; with the parallel MR850 system, respective AH readings were $32.8 \mathrm{mg} / \mathrm{mL}(31.9-34.4)$, $33.0 \mathrm{mg} / \mathrm{mL}(32.0-34.4), 33.0 \mathrm{mg} / \mathrm{mL}(32.0-34.4)$, $32.8 \mathrm{mg} / \mathrm{mL}(31.4-33.7), 32.5 \mathrm{mg} / \mathrm{mL}(31.7-34.1)$, and $32.9 \mathrm{mg} / \mathrm{mL}$ (31.8-34.4). With the single MR850 system, as gas flow increased in increments of $10 \mathrm{~L} / \mathrm{min}$ from 40-60 L/min, AH remained constant. At flows above 80 $\mathrm{L} / \mathrm{min}$, however, AH decreased $(P<.001)$. With the Hummax 2 system, as flow increased, AH decreased $(P<.001)$. With the parallel MR850 system, AH remained constant regardless of gas flow (Fig. 4).

\section{Effect of $V_{T}$ on $\mathrm{AH}$}

With the single MR850 system, at very-high gas flows of 40,50 , and $60 \mathrm{~L} / \mathrm{min}$, as $\mathrm{V}_{\mathrm{T}}$ increased, $\mathrm{AH}$ increased. When the gas flow was $>70 \mathrm{~L} / \mathrm{min}$, AH remained the same when $\mathrm{V}_{\mathrm{T}}$ was 500 and $700 \mathrm{~mL}$. With the Hummax 2 system, at gas flows of 40 and $50 \mathrm{~L} / \mathrm{min}$, as $\mathrm{V}_{\mathrm{T}}$ increased, AH increased; at gas flows $60-80 \mathrm{~L} / \mathrm{min}$, when $\mathrm{V}_{\mathrm{T}}$ changed from 500 to $700 \mathrm{~mL}$, AH was affected by $\mathrm{V}_{\mathrm{T}}$; at a flow of $90 \mathrm{~L} / \mathrm{min}$, however, $\mathrm{AH}$ was not affected by variations in $\mathrm{V}_{\mathrm{T}}$. With the parallel MR850 system, as $\mathrm{V}_{\mathrm{T}}$ increased, $\mathrm{AH}$ increased (Table 1, Fig. 5).

\section{Effect of Breathing Frequency on AH}

With each of the tested systems, as breathing frequency increased, AH increased $(P<.001)$ (Fig. 6).

\section{Discussion}

In this study, we tested various simulated spontaneous breathing patterns to investigate how well 3 types of heated humidifiers maintained humidification during HFNC therapy with very high gas flow. When flow was $>70 \mathrm{~L} / \mathrm{min}$, neither the single MR850 system nor the Hummax2 system maintained $\mathrm{AH}$ at $30 \mathrm{mg} / \mathrm{L}$. At flows of up to 90 $\mathrm{L} / \mathrm{min}$, the parallel MR850 system consistently maintained $\mathrm{AH}$ at $>30 \mathrm{mg} / \mathrm{L}$.

\section{Effect of HFNC Gas Flow on AH}

Chikata et $\mathrm{al}^{3}$ conducted bench-study evaluations of humidification performance during HFNC therapy, and they found that $\mathrm{AH}$ values with an MR850 were $33.1 \pm 1.5$ $\mathrm{mg} / \mathrm{mL}, 35.9 \pm 1.7 \mathrm{mg} / \mathrm{mL}$, and $36.2 \pm 1.7 \mathrm{mg} / \mathrm{L}$ at gas flows of 20,40 , and $50 \mathrm{~L} / \mathrm{min}$, respectively. Internal condensation varied according to ambient temperature; the lower the temperature, the greater the volume of condensate. In our study, AH was lower at gas flows of 40 and $50 \mathrm{~L} / \mathrm{min}$ than in their study, possibly due to the higher ambient temperature in ths study $\left(25.6 \pm 0.5^{\circ} \mathrm{C}\right.$ vs $\left.24.1 \pm 0.2^{\circ} \mathrm{C}\right)$.

With the single MR850 system, as very-high gas flow increased, AH increased, and at gas flows $>80 \mathrm{~L} / \mathrm{min}$, $\mathrm{AH}$ decreased. Chikata et $\mathrm{al}^{3}$ reported that as gas flow increased, the $\mathrm{AH}$ of inspired gas increased. At gas flows of $60 \mathrm{~L} / \mathrm{min}$ or more, the electrical output of the humidifier heater plates was continuously $100 \%$ and the 
Table 1. Effect of $\mathrm{V}_{\mathrm{T}}$ and Gas Flow on Absolute Humidity

\begin{tabular}{|c|c|c|c|c|}
\hline \multirow{2}{*}{ HFNC System } & \multirow{2}{*}{ Flow (L/min) } & \multicolumn{3}{|c|}{ Absolute Humidity, mg/L } \\
\hline & & $\mathrm{V}_{\mathrm{T}}=300 \mathrm{~mL}$ & $\mathrm{~V}_{\mathrm{T}}=500 \mathrm{~mL}$ & $\mathrm{~V}_{\mathrm{T}}=700 \mathrm{~mL}$ \\
\hline \multirow[t]{6}{*}{ Single MR850 } & 40 & $32.6(31.4-33.8)$ & $33.6(32.6-34.7)$ & $33.7(32.8-35.5)$ \\
\hline & 50 & $33.1(31.9-34.4)$ & $34.4(32.7-36.3)$ & $34.9(33.7-36.4)$ \\
\hline & 60 & $34.2(32.5-36.0)$ & $35.4(34.1-36.7)$ & $35.9(35.6-36.9)$ \\
\hline & 70 & $35.3(33.3-36.2)$ & $35.4(34.3-36.5)$ & $35.4(35.2-36.8)$ \\
\hline & 80 & $30.4(28.8-32.0)$ & $32.0(30.3-33.5)$ & $31.5(31.3-33.2)$ \\
\hline & 90 & $28.9(27.8-30.1)$ & $29.9(28.8-31.1)$ & $30.1(29.1-31.2)$ \\
\hline \multirow[t]{6}{*}{ Hummax 2} & 40 & $33.6(32.5-34.5)$ & $34.6(33.1-35.9)$ & $35.5(34.0-37.0)$ \\
\hline & 50 & $33.4(32.5-34.0)$ & $33.7(31.7-35.6)$ & $34.9(33.2-36.6)$ \\
\hline & 60 & $32.0(31.3-32.4)$ & $31.7(29.9-33.5)$ & $32.8(31.8-33.8)$ \\
\hline & 70 & $28.4(27.3-29.4)$ & $28.9(28.0-29.7)$ & $31.5(30.6-32.4)$ \\
\hline & 80 & $27.7(27.0-28.5)$ & $27.6(26.9-28.3)$ & $28.3(27.5-29.2)$ \\
\hline & 90 & $26.9(26.7-27.2)$ & $26.9(26.6-27.0)$ & $26.7(25.0-28.2)$ \\
\hline \multirow[t]{6}{*}{ Parallel MR850 } & 40 & $32.0(30.5-33.5)$ & $33.2(32.0-34.4)$ & $33.7(32.1-35.2)$ \\
\hline & 50 & $32.8(32.0-33.6)$ & $33.2(32.0-34.4)$ & $33.8(32.5-35.0)$ \\
\hline & 60 & $32.2(31.2-33.3)$ & $33.2(32.0-34.4)$ & $33.8(32.7-35.0)$ \\
\hline & 70 & $32.0(30.8-33.2)$ & $32.6(31.4-33.7)$ & $33.4(32.3-34.8)$ \\
\hline & 80 & $32.1(31.0-33.3)$ & $32.9(31.7-34.1)$ & $33.3(31.9-34.7)$ \\
\hline & 90 & $32.0(30.8-33.3)$ & $33.2(31.8-34.4)$ & $33.7(32.5-34.7)$ \\
\hline
\end{tabular}

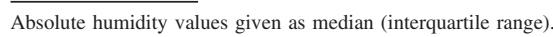

$\mathrm{V}_{\mathrm{T}}=$ tidal volume

humidifier-outlet and tube-end temperatures were lower than set, a limit that restricted the amount of vapor the MR850 could deliver ${ }^{10}$; consequently, as gas flow increased, AH decreased. With the Hummax2, at each increment, as very-high gas flow increased, AH decreased. With the single MR850 and the Hummax 2 systems, at gas flows $>60 \mathrm{~L} / \mathrm{min}$, temperature was unstable (Fig. 7); fluctuations were more pronounced with the Hummax 2 than with the single MR850. By contrast, in the parallel MR850 system, temperature remained stable. The Hummax 2 uses a porous hollow polyethylene fiber membrane, and the temperature is servo-controlled by sensing temperature only at the distal end of the tube away from the water reservoir; the system design delivered less vapor in our test protocols. With the parallel MR850 system, during HFNC therapy, maximum gas flow through each heated humidifier was 45 $\mathrm{L} / \mathrm{min}$. At gas flows of $40 \mathrm{~L} / \mathrm{min}$ or less, the temperature at the outlet of the water reservoir and at the end of the inspiratory tube remained at the set temperature, and the electrical output of the heated humidifier heater plates was $<100 \%$.

\section{Effect of $V_{T}$ and Breathing Frequency on $\mathrm{AH}$}

With the single MR850 system, at very-high gas flows of 40,50 and $60 \mathrm{~L} / \mathrm{min}$, as $\mathrm{V}_{\mathrm{T}}$ increased, $\mathrm{AH}$ increased. When gas flow increased to $>70 \mathrm{~L} / \mathrm{min}$, the effect on $\mathrm{AH}$ was negligible when $\mathrm{V}_{\mathrm{T}}$ varied between 500 and $700 \mathrm{~mL}$. With the Hummax2, at very-high gas flows of 40 and $50 \mathrm{~L} / \mathrm{min}$, as $\mathrm{V}_{\mathrm{T}}$ increased, $\mathrm{AH}$ increased. As shown in Figure 4 , as $\mathrm{V}_{\mathrm{T}}$ increased, these 2 systems were unable to maintain the desired levels of $\mathrm{AH}$ at higher levels of gas flow; the Humamx2 performed inconsistently at HFNC flows $>60 \mathrm{~L} / \mathrm{min}$, and the single MR850 performed inconsistently at levels $>80 \mathrm{~L} / \mathrm{min}$. By contrast, regardless of $\mathrm{V}_{\mathrm{T}}$ setting, the parallel MR850 system reliably delivered adequate $\mathrm{AH}$.

Humidity during HFNC therapy depends on both inspiratory flow of spontaneous breathing and gas flow. When spontaneous breathing inspiratory flow is less than the gas flow, in theory, patients would inspire only the gas delivered via the cannula, and thus, due to the high flow, adequate humidification of the gas reaching the lungs would depend on adequate humidification of the delivered gas. On the other hand, when the inspiratory flow of spontaneous breathing is greater than the gas flow, patients inspire a mixture of delivered gas and room air. When $\mathrm{V}_{\mathrm{T}}$ was set at 300,500 , and $700 \mathrm{~mL}$, and inspiratory time was set at $1.0 \mathrm{~s}$ with a decelerating flow waveform, peak inspiratory flows of spontaneous breathing were 33,55 , and $77 \mathrm{~L} / \mathrm{min}$, respectively. Consequently, at each $\mathrm{V}_{\mathrm{T}}$ setting, when gas flow is $>80 \mathrm{~L} / \mathrm{min}$, patients would, in theory, inhale only gas. In spontaneous breathing, inspiratory gas is normally heated and humidified in the nasal cavity and pharynx. Due to the higher gas flow during HFNC ther- 

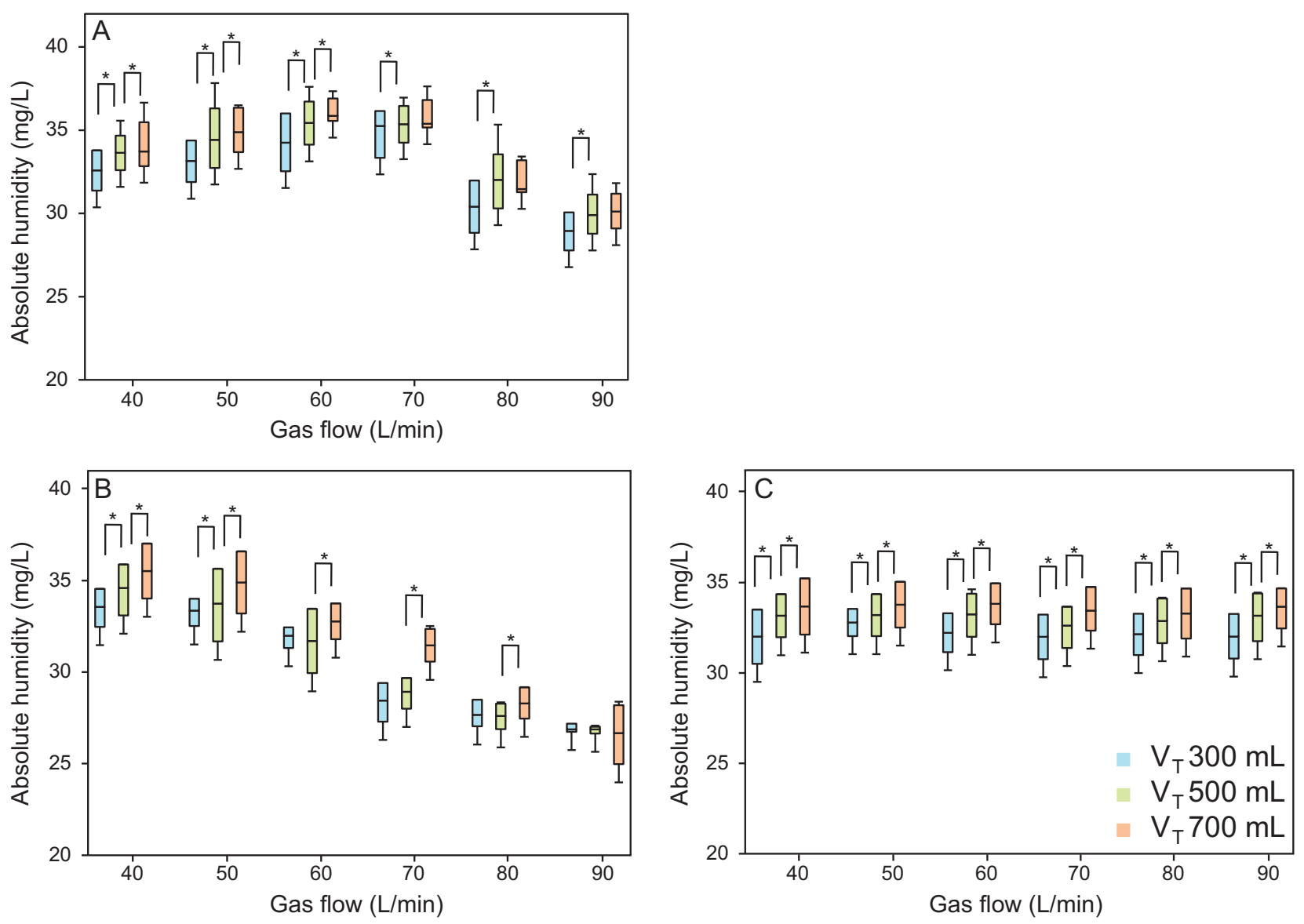

Fig. 5. With the single MR850, at HFNC gas flow of 40,50 and $60 \mathrm{~L} / \mathrm{min}$, as $\mathrm{V}_{\mathrm{T}}$ increased, $\mathrm{AH}$ increased. At HFNC gas flows greater than $70 \mathrm{~L} / \mathrm{min}$, when $\mathrm{V}_{\mathrm{T}}$ varied between 500 to $700 \mathrm{~mL}$, $\mathrm{AH}$ was not affected. With the Hummax2, at HFNC gas flow 40 and $50 \mathrm{~L} / \mathrm{min}$, as $\mathrm{V}_{\mathrm{T}}$ increased, $\mathrm{AH}$ increased. At flow of $60-80 \mathrm{~L} / \mathrm{min}$, when increased to $700 \mathrm{~mL}, \mathrm{~V}_{\mathrm{T}}$ affected $\mathrm{AH}$. With the parallel $\mathrm{MR} 850 \mathrm{~s}$, as $\mathrm{V}_{\mathrm{T}}$ increased, $\mathrm{AH}$ increased at all HFNC gas flow settings.

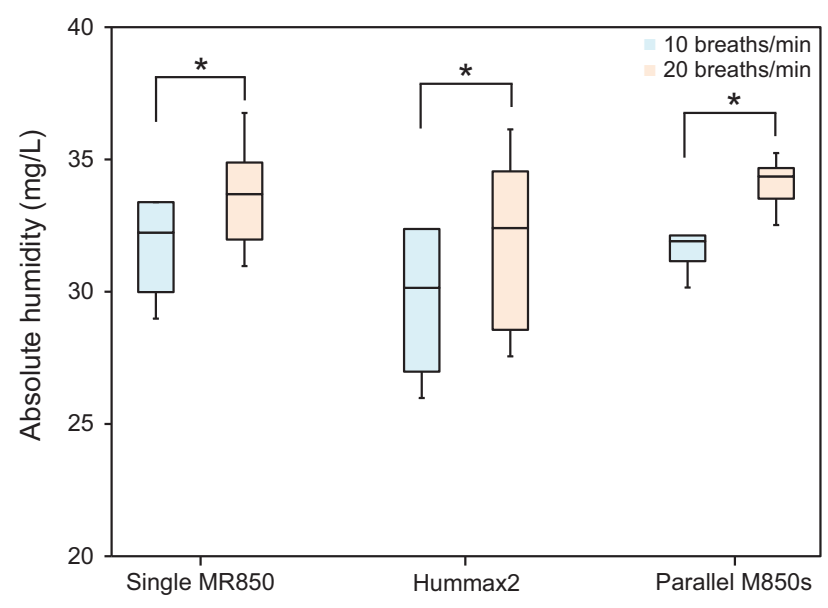

Fig. 6. Effect of breathing frequency. With each of the tested systems, as breathing frequency increased, absolute humidity increased. apy, humidification performance is much more heavily dependent on the humidity of the inspired gas and room air. Although we made the distance between the external nares and hygrometer as short as we could, it is likely that inspired gas temperature was affected by ambient air temperature. In addition, as $\mathrm{V}_{\mathrm{T}}$ at a fixed inspiratory time of $1.0 \mathrm{~s}$ increased, inspiratory flow increased. Because the inspiratory flow of simulated spontaneous breathing is more rapid, gas at HFNC flow levels remains in the simulated nasal cavity and pharynx for less time, and, consequently, the medical gas is less cooled. With the single MR850 system and the Hummax2, at very-high gas flows (ie, $>60 \mathrm{~L} / \mathrm{min}$ ), the servo-control of the heated humidifier was unreliable. As a result, the 2 single-humidifier systems showed inconsistencies at higher levels of gas flow.

As breathing frequency increased, $\mathrm{AH}$ increased, and the time between breaths decreased. Therefore, there are few effects of environmental temperature in this bench study. 

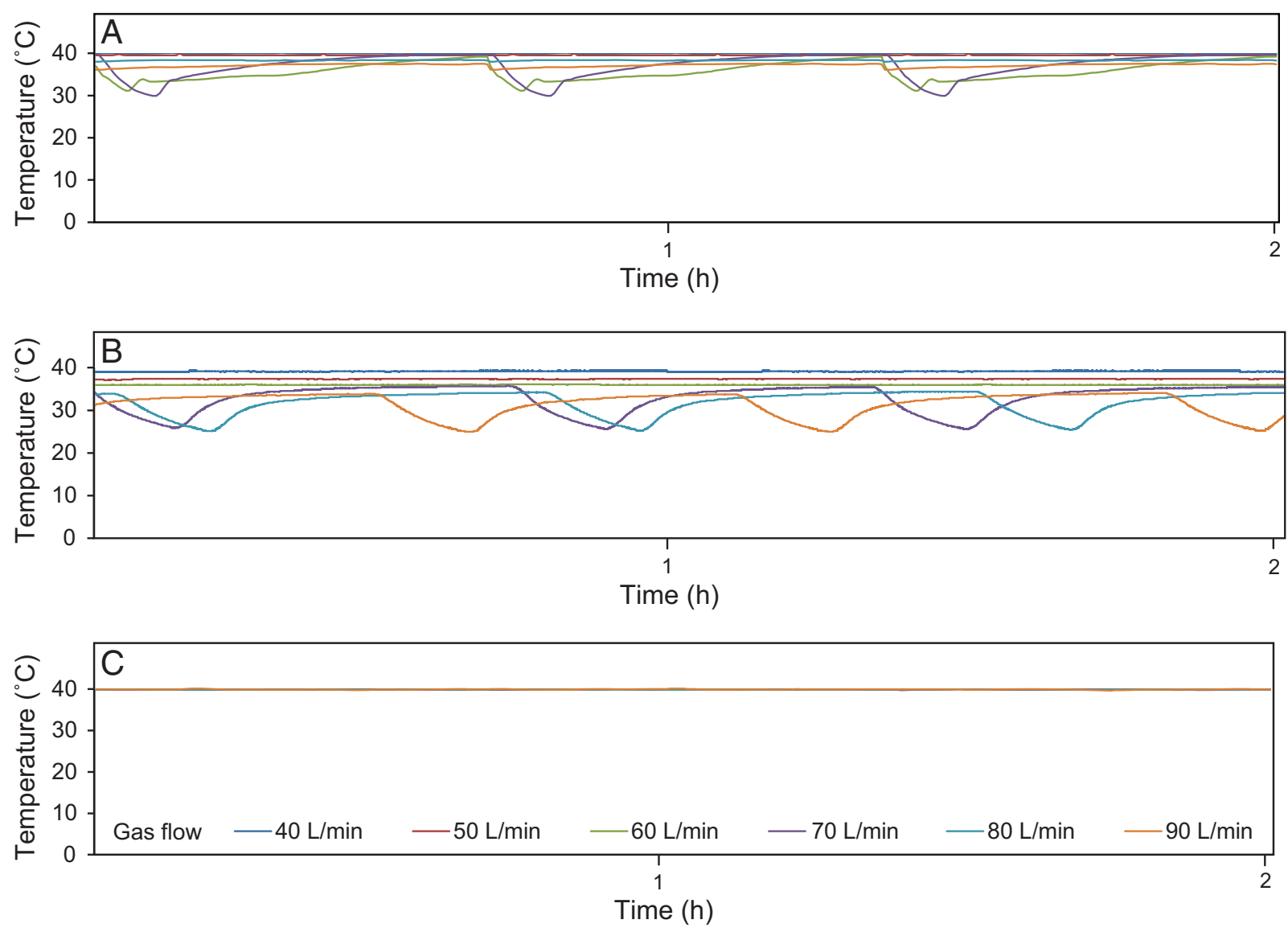

Fig. 7. Temperature at tube end in each system. Distal temperature in tubes was measured for 60 min in each device at each high-flow gas flow setting. A: Single MR850 set at $40^{\circ} \mathrm{C}$, B: Hummax2 set at $39^{\circ} \mathrm{C}$, and C: parallel MR850s set at $40^{\circ} \mathrm{C}$. With both single humidifier systems, at HFNC gas flows greater than $60 \mathrm{~L} / \mathrm{min}$, the temperature was not stable. Both the frequency and degree of inconsistency was greater with the Hummax2 than with the single MR850. With the parallel MR850s, temperature remained stable.

\section{Limitations}

Aside from being a bench study, the findings of which cannot be directly applied to clinical settings, our experiment has some limitations. First, our study used a closedmouth simulation. Real patients, if breathing through the mouth, would inspire more ambient air. In addition, actual human $\mathrm{V}_{\mathrm{T}}$ varies and, in real lungs, actual $\mathrm{AH}$ might vary breath-by-breath. ${ }^{11}$ Second, the study was done using only one inspiratory flow waveform; in real life, peak inspiratory flow varies from patient to patient and from breath to breath. The $V_{T}$ of patients with respiratory failure is greater than the $V_{T}$ settings we tested. Finally, we had difficulty simulating a comprised oropharynx and the dead space associated with such compromise.

\section{Conclusions}

Using a lung model and various respiratory patterns, we evaluated the humidification performance of 3 heated humidifier systems during HFNC with very high gas flow. At gas flows $>60 \mathrm{~L} / \mathrm{min}$, the 2 single-humidifier systems we tested were unable to reliably maintain the set temperature. However, 2 MR850 devices set up in parallel were able to maintain set temperature in all gas flow settings. When using the $\mathrm{O}_{2}$ /air blenders at very high flows for patients, we recommend using parallel heated humidifiers and carefully observing vital signs and sputum characteristics.

\section{REFERENCES}

1. Nishimura M. High flow nasal cannula oxygen therapy in adults. J Intensive Care 2015;3(1):15.

2. Frizzola M, Miller TL, Rodriguez ME, Zhu Y, Rojas J, Hesek A, et al. High-flow nasal cannula: impact on oxygenation and ventilation in an acute lung injury model. Pediatr Pulmonol 2011;46(1):67-74.

3. Chikata Y, Izawa M, Okuda N, Itagaki T, Nakataki E, et al. Humidification performance of two high-flow nasal cannula devices: a bench study. Respir Care 2014;59(8):1186-90.

4. Chikata $\mathrm{Y}$, Onodera M, Oto J, Nishimura $\mathrm{M}$. $\mathrm{F}_{\mathrm{IO}_{2}}$ in an adult model simulating high-flow nasal cannula therapy. Respir Care 2017;62(2): 193-98.

5. Parke RL, Guinness SM, Eccleston M. Nasal high-flow therapy delivers low level positive airway pressure. BJA 2009;103:886-90. 


\section{Simulated Humidification in Very-High-Flow Nasal Cannula}

6. Groves N, Tobin A. High-flow nasal oxygen generates positive airway pressure in adult volunteers. Aust Crit Care 2007;20:126-31.

7. Delorme M, Bouchard PA, Simon M, Simard S, Lellouche F. Effects of high-flow nasal cannula on the work of breathing in patients recovering from acute respiratory failure. Crit Care Med 2017;45(12): 1981-88.

8. Parke RL, Bloch A, McGuinness SP. Effect of very high-flow nasal therapy on airway pressure and end-expiratory lung impedance in healthy volunteers. Respir Care 2015;60(10):1397-403.
9. Danin PE, Dellamonica J, Bernardin G. Precautions with humidifier systems in particular environments. Intensive Care Med 2013;39(8): 1504.

10. Chikata Y, Unai K, Izawa M, Okuda N, Oto J, Nishimura M. Inspiratory tube condensation during high-flow nasal cannula therapy: a bench study. Respir Care 2016;61(3):300-305.

11. Askanazi J, Silverberg PA, Hyman AI, Rosenbaum SH, Foster R, Kinney JM. Patterns of ventilation in postoperative and acutely ill patients. Crit Care Med 197(2)9;7:41-46. 